\title{
Comparative Study of Optimization Methods for Estimation of Sea Surface Temperature and Ocean Wind with Microwave Radiometer Data
}

\author{
Kohei Arai ${ }^{1}$ \\ Graduate School of Science and Engineering \\ Saga University \\ Saga City, Japan
}

\begin{abstract}
Comparative study of optimization methods for estimation sea surface temperature and ocean wind with microwave radiometer data is conducted. The well known mesh method (Grid Search Method: GSM), regressive method, and simulated annealing method are compared. Surface emissivity is estimated with the simulated annealing and compared to the well known Thomas T. Wilheit model based emissivity. On the other hand, brightness temperature of microwave radiometer as a function of observation angle is estimated by the simulated annealing method and compares it to the actual microwave radiometer data. Also, simultaneous estimation of sea surface temperature and ocean wind speed is carried out by the simulated annealing and compared it to the estimated those by the GSM method. The experimental results show the simulated annealing which allows estimation of global optimum is superior to the other method in some extent.
\end{abstract}

Keywords-Microwave radiometer; remote sensing; sea surface temperature; nonlinear optimization theory; simulated annealing

\section{INTRODUCTION}

Microwave scanning radiometer allows estimation of geophysical parameters such as soil moisture, salinity, ocean wind, sea surface temperature, water vapor, cloud liquid, and so on with all weather conditions and in day and night basis [1]-[24]. Several microwave radiometers are carried on the several satellites and used for weather prediction and climate change research. One of the major concerns on the microwave radiometer is estimation accuracy of the geophysical parameters. Most of the methods for estimation of geophysical parameters are based on statistical models, regressive analysis. The estimation accuracy is not good enough because the regressive coefficients are determined with some observation conditions, areas of concerns, specific seasons. Therefore, the estimation accuracy is not good enough when the actual conditions are not matched to the conditions for the determination of regressive coefficients. Other than this, there is physical model based approaches. Through minimization processes between the actual acquired brightness temperature and the estimated brightness temperature derived from the model based method.

Microwave radiometer allows estimation of geophysical parameters such as water vapor, rainfall rate, ocean wind speed, salinity, soil moisture, air-temperature, sea surface temperature, cloud liquid, etc. based on least square method. Due to the fact that relation between microwave radiometer data (at sensor brightness temperature at the specified frequency) and geophysical parameters is non-linear, non-linear least square method is required for the estimations. Although there are some methods which allow estimation optimum solutions, Simulated Annealing: SA method [25] is just one method for finding global optimum solution.

Other methods, such as steepest descending method, conjugate gradient method, etc. gives one of local minima, not the global optimum solution. SA, on the other hand, requires huge computer resources for convergence. In order to accelerate the convergence process, not the conventional exponential function with the temperature control, but osculated decreasing function is employed for cool down function. Geophysical parameter estimation based on simulated annealing is proposed previously [6]. It takes relatively long computational time for convergence. Moreover, optimization with constraints makes much accurate estimation of geophysical parameters. Some of the constraints is relation among the geophysical parameters.

Geophysical parameters have relations each other. For instance, sea surface temperature and water vapor has a positive relation, in general. Therefore, it is better to estimate several geophysical parameters simultaneously rather than the estimation for single parameter. The proposed method is based on modified SA algorithm and is for simultaneous estimation for several geophysical parameters at once. Some experiments are conducted with Advanced Microwave Scanning Radiometer: AMSR [2] onboard AQUA satellite. Then it is confirmed that the proposed method surely works for improvement of estimation accuracy for all the geophysical parameters.

The related research works is described the following section. Then the proposed method is described followed by experiments. The experimental results are validated in the following section followed by conclusion with some discussions.

\section{RELATED RESEARCH WORKS}

\section{A. Geophysical Parameter Estimation by Regressive Analysis}

There are some atmospheric and ocean surface models in the microwave wavelength region. Therefore, it is possible to 
estimate at sensor brightness temperature (microwave radiometer) with the geophysical parameters. The real and the imaginary part of dielectric constant of the calm ocean surface is modeled with the SST, salinity (conductivity). From the dielectric constant, reflectance of the ocean surface is estimated together with the emissivity (Debue, 1929 [26]; Cole and Cole,1941 [27]). There are some geometric optics ocean surface models (Cox and Munk, 1954 [28]; Wilheit and Chang, 1980 [29]). According to the Wilheit model, the slant angle against the averaged ocean surface is expressed by Gaussian distribution function.

There is a relation between ocean wind speed and the variance of the Gaussian distribution function as a function of the observation frequency. Meanwhile the influence due to foams, white caps on the emissivity estimation is expressed with the wind speed and the observation frequency so that the emissivity of the ocean surface and wind speed is estimated with the observation frequency simultaneously. Meanwhile, the atmospheric absorptions due to oxygen, water vapor and liquid water were well modeled (Waters, 1976 [30]). Then atmospheric attenuation and the radiation from the atmosphere can be estimated using the models. Thus the at-sensorbrightness temperature is estimated with the assumed geophysical parameters.

Sea surface temperature estimation methods with AMSR data are proposed and published [31] while ocean wind retrieval methods with AMSR data are also proposed and investigated [32]. Furthermore, water vapor and cloud liquid estimation methods with AMSR data are proposed and studied [33]. The conventional geophysical parameter estimation method is based on regressive analysis with a plenty of truth data and the corresponding microwave radiometer data [34].

The brightness temperature which acquired with microwave radiometer depends on geophysical parameters, (1) Sea Surface Temperature: SST, (2) ocean Wind Speed: WS, (3) Cloud Liquid: CL, (4) Water Vapor: WV in the atmosphere, (5) Salinity: SAL, etc. Also, the brightness temperature depends on observation frequency and abservation angle.

There are physical model based approach and statistical model based approach. The most typical statistical model is proposed by Frank Wentz [33]. His model is expressed with the following second order of equation,

$$
\text { Geophysical }(x)=\mathrm{c}_{0}+\sum \mathrm{a}_{\mathrm{i}} \mathrm{T}_{\mathrm{Bi}}+\sum \mathrm{b}_{\mathrm{i}} \mathrm{T}_{\mathrm{Bi}}^{2}
$$

where Geophysical $(x)$ denotes geophysical parameter of $(x)$ while $a_{i}, b_{i}$ denotes regressive coefficients while $T_{B i}$ denotes observed brightness temperature with microwave radiometer, respectively. When truth data of the geophysical parameter are given, then regressive coefficients are derived through regressive analysis.

Once the regressive coefficients, geophysical parameter can be estimated with the regressive equation and the observed brightness temperature. Example of the regressive coefficients for geophysical parameter of SST for Advanced Microwave Scanning Radiometer: AMSR of the $10 \mathrm{GHz}$ frequency band which is carried by AQUA, etc. is shown in Table 1 .
TABLE I. EXAMPLE OF THE REGRESSIVE COEFFICIENTS FOR GeOPHySicAl Parameter of SEA SuRface TEMPERATURE

\begin{tabular}{|l|l|}
\hline & Coefficient \\
\hline $\mathrm{c}_{\mathrm{o}}$ & 122.317 \\
\hline $\mathrm{a}_{1}$ & 2.1117 \\
\hline $\mathrm{a}_{2}$ & 0.9079 \\
\hline $\mathrm{a}_{3}$ & 0.4618 \\
\hline $\mathrm{a}_{4}$ & -0.6192 \\
\hline $\mathrm{a}_{5}$ & -1.0579 \\
\hline $\mathrm{a}_{6}$ & 0.6242 \\
\hline $\mathrm{a}_{7}$ & -8.915 \\
\hline $\mathrm{a}_{8}$ & 25.6123 \\
\hline $\mathrm{a}_{9}$ & -0.4318 \\
\hline $\mathrm{a}_{10}$ & 0.2244 \\
\hline $\mathrm{b}_{1}$ & 0.0335 \\
\hline $\mathrm{b}_{2}$ & 0.00468 \\
\hline $\mathrm{b}_{3}$ & -0.0293 \\
\hline $\mathrm{b}_{4}$ & 0.003914 \\
\hline $\mathrm{b}_{5}$ & -0.4718 \\
\hline $\mathrm{b}_{6}$ & 0.000753 \\
\hline $\mathrm{b}_{7}$ & -5.9235 \\
\hline $\mathrm{b}_{8}$ & 5.4932 \\
\hline $\mathrm{b}_{9}$ & 0.001703 \\
\hline $\mathrm{b}_{10}$ & 0.0001107 \\
\hline
\end{tabular}

Although this regressive approach is convenient and ensures a marginal accuracy, it is not enough SST estimation accuracy. It depends on the ocean areas, seasons, etc. Therefore, the regressive equation with only one set of coefficients cannot cover these dependencies which results in not so good estimation accuracy.

\section{B. Physical Model Based Approach}

Minimizing the difference between a geophysical model based Brightness Temperature: $\mathrm{T}_{\mathrm{m}}$ and an acquired actual Brightness Temperature: $T_{a}$, input parameter of geophysical parameter can be estimated. $\mathrm{T}_{\mathrm{a}}$, depends on the observation frequency, observation angle, and the geophysical parameters as mentioned above. The observation frequency and angle is known. Therefore, the geophysical parameters can be estimated through minimization of the difference between both of $\mathrm{T}_{\mathrm{m}}$ and $\mathrm{T}_{\mathrm{a}}$. The important thing for this approach is accurate geophysical model. There is the well known sea surface model which is proposed by Thomas T. Wilheit [28].

\section{PROPOSED MODEL}

\section{A. Basic Idea}

The brightness temperatures of the several observation frequency bands can be acquired in both horizontal and vertical polarizations. If the users focus water vapor and cloud liquid, then $23 \mathrm{GHz}$ and $31 \mathrm{GHz}$ of observation frequency bands are needed. It is totally up to frequency dependency of brightness temperature of frequency. There is strong absorption of water vapor at the $23.235 \mathrm{GHz}$ while dual frequency channels allow simultaneous estimation of water vapor and cloud liquid. Therefore, $23 \mathrm{GHz}$ and $31 \mathrm{GHz}$ of frequency bands are effective for water vapor and cloud liquid estimations. And if we focus SST and wind speed, only 6.925 and $10.69 \mathrm{GHz}$ of observation frequency bands are taken into account. In this paper, targeted geophysical parameters are SST and Wind Speed. 
The observed brightness temperature at the certain frequency band in horizontal and vertical polarizations are expressed as follows,

$$
\begin{aligned}
& \mathrm{T}_{\mathrm{bh}}=\varepsilon_{\mathrm{h}}(\mathrm{T}, \mathrm{W}) \mathrm{T}+\mathrm{n}_{\mathrm{h}} \\
& \mathrm{T}_{\mathrm{bv}}=\varepsilon_{\mathrm{v}}(\mathrm{T}, \mathrm{W}) \mathrm{T}+\mathrm{n}_{\mathrm{v}}
\end{aligned}
$$

where $\mathrm{T}_{\mathrm{bh}}, \varepsilon_{\mathrm{h}}, \mathrm{T}, \mathrm{W}, \mathrm{n}_{\mathrm{h}}$ denotes brightness temperature, emissivity of the sea surface, Planck function of surface temperature, ocean wind speed, and observation noise for horizontal polarization while these for suffix of $v$ denotes those for vertical polarization. Cost function of optimization processes is defined as follows,

$$
\left\|\mathrm{T}_{\mathrm{bh}}-\varepsilon_{\mathrm{h}}(\mathrm{T}, \mathrm{W}) \mathrm{T}\right\|^{2}+\left\|\mathrm{T}_{\mathrm{bv}}-\varepsilon_{\mathrm{v}}(\mathrm{T}, \mathrm{W}) \mathrm{T}\right\|^{2}
$$

Minimizing the cost function of equation (4) with the changing the input parameter of $\mathrm{T}$ and $\mathrm{W}, \mathrm{T}$ and $\mathrm{W}$ can be estimated by using the observed brightness temperature. The most important thing for this method is how to estimate sea surface emissivity. In accordance with the Wilheit model, emissivity in horizontal and vertical polarizations is estimated. Fig. 1 shows the example of the calculated emissivity.

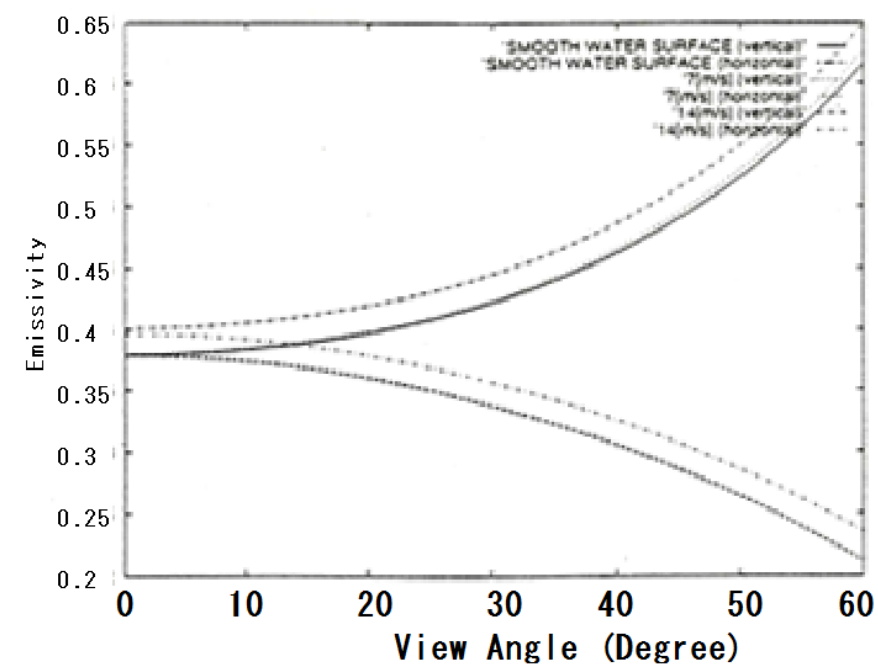

Fig. 1. Emissivity model originated from the Wilheit model

\section{B. Simulated Annealing}

The proposed geophysical parameter estimation here is based on the physical model based approach. Minimization of the difference between $\mathrm{T}_{\mathrm{m}}$ and $\mathrm{T}_{\mathrm{a}}$, is total identical to optimization model. The problem situated here is how to find the global optimum. Only the solution for that is Simulated Annealing: SA. It, however, takes huge computational resources. Therefore, the proposed model here is modified SA model which has a limitation of iteration. Namely, iterations is stopped at the previously designated upper limit. Therefore, the proposed modified SA is not real SA essentially because the solution does not reach to a global optimum. In the case of the estimation of geophysical parameter with microwave radiometer data, residual error is gradually reduced when the current solution is approaching to a global optimum (the solution does not jump in this stage). Therefore, we may stop the iteration at the certain number of iterations or elapsed computation time.

\section{EXPERIMENTS}

\section{A. Validation of Emissivity Model}

As an example of brightness temperature, the brightness temperature of Microwave Imager: TMI onboard Tropical Rainfall Measuring Mission: TRMM satellite of $10.65 \mathrm{GHz}$ for horizontal and vertical polarizations is shown in Fig.2. The actual brightness temperature as a function of observation angle is plotted in Fig.2. The location of intensive study area is the following,

Longitude and latitude: 31.6 North, 109.1 East

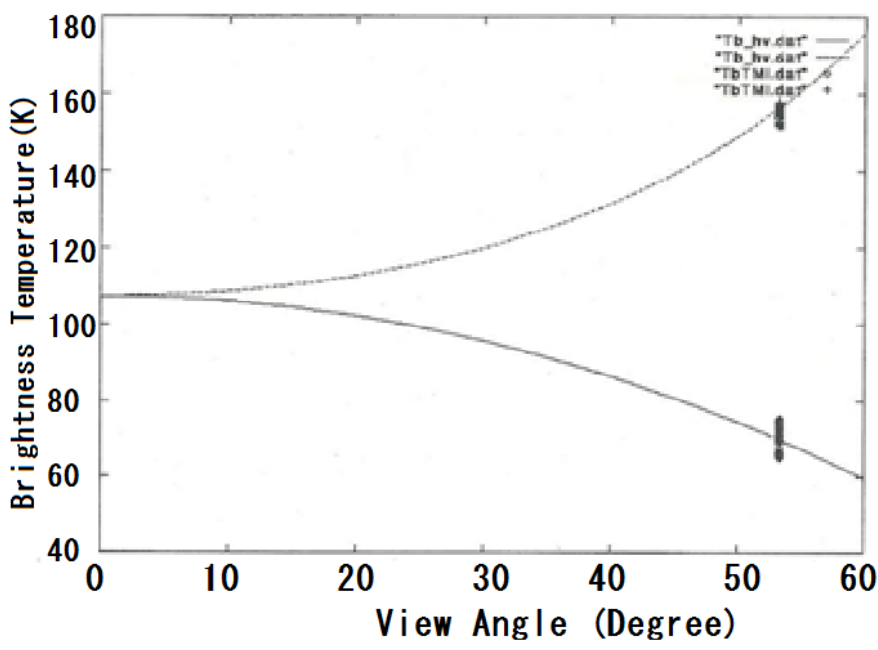

Fig. 2. Brightness temperature for both horizontal and vertical polarizations derived from the proposed physical model based method and actual received brightness temperature with TRMM/TMI of $10.65 \mathrm{GHz}$ of frequency channel acquired on June 21998

The actual brightness temperature data are situated at the observation angle of 53 degree because the brightness temperature for horizontal polarization does not depend on ocean wind speed at the observation angle of 53 degree. The estimated brightness temperature is coincident to the actual brightness temperature. This is the same thing for the different observation frequency and both of horizontal and vertical polarizations. Therefore, emissivity model originated from the Wilheit model is validated.

The actual TMI data of the location (Longitude and latitude: 31.6 North, 109.1 East) which is acquired on June 2 1998 is used for the experiment. From the measured data at the site, it is found that $\mathrm{SST}=294 \mathrm{~K}, \mathrm{WS}=7 \mathrm{~m} / \mathrm{s}$, Salinity=36ppm, respectively. The truth geophysical parameters of SST are set at $292 \mathrm{~K}, 294 \mathrm{~K}$, and $296 \mathrm{~K}$ while that of wind speed is set at 7 $\mathrm{m} / \mathrm{s}$. The brightness temperature estimated by the proposed physical model based method. The results are as follows,

\section{1) Theoretical brightness temperature: 70.549}

The mean of observed brightness temperature: 100.589

The standard deviation of the actual brightness temperature: 9.634

2) Theoretical brightness temperature: 156.574

The mean of observed brightness temperature: 173.814 

2.906

The standard deviation of the actual brightness temperature:

3) Theoretical brightness temperature: 70.3

The mean of observed brightness temperature: 100.589 9.635

The standard deviation of the actual brightness temperature:

4) Theoretical brightness temperature: 155.905

The mean of observed brightness temperature: 173.814

The standard deviation of the actual brightness temperature: 2.906

5) Theoretical brightness temperature: 70.081

The mean of observed brightness temperature: 100.589

The standard deviation of the actual brightness temperature: 9.635

6) Theoretical brightness temperature: 155.284

The mean of observed brightness temperature: 173.814 2.906

The standard deviation of the actual brightness temperature:

Thus the proposed model is validated with some extent of estimation errors.

\section{B. Comparison of Estimated Sea Surface Temperature}

In order to show the advantage of the proposed method, the estimated SST and WS with the proposed method is compared to those with the statistical model based method, conventional GSM method. Fig.3 shows the results from the comparative study. In the experiment, observation frequency channels are set at $6.925 \mathrm{GHz}$ and $10.69 \mathrm{GHz}$. Fig.3 shows RMS error of SST and WS with the designated biases of plus minus $1(\mathrm{~K})$, $3(\mathrm{~K})$ for SST and plus minus $1(\mathrm{~m} / \mathrm{s}), 3(\mathrm{~m} / \mathrm{s})$ for WS as well as without any bias for the proposed SA based method and the conventional GSM method.



(a)SST for SA

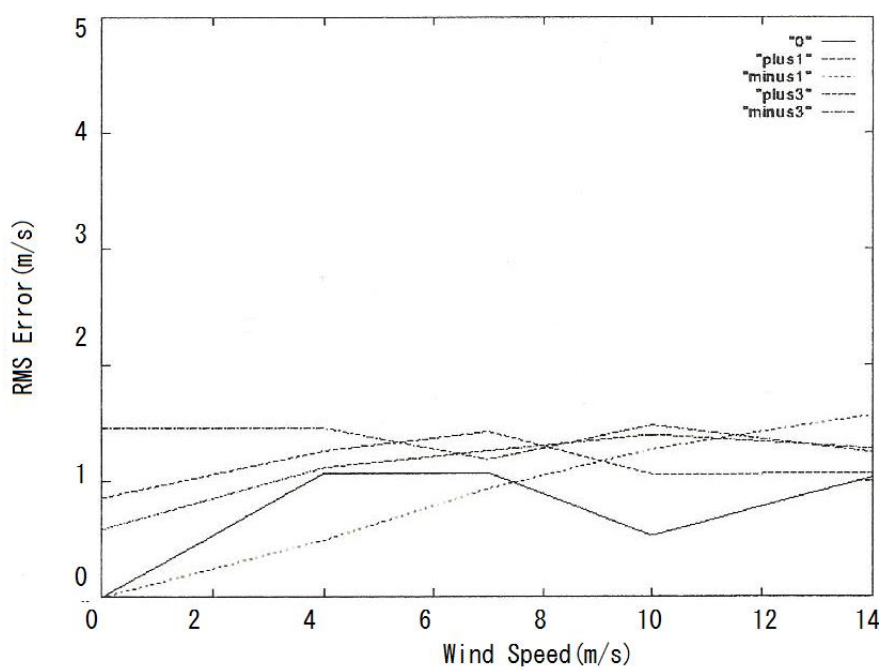

(b)WS for SA
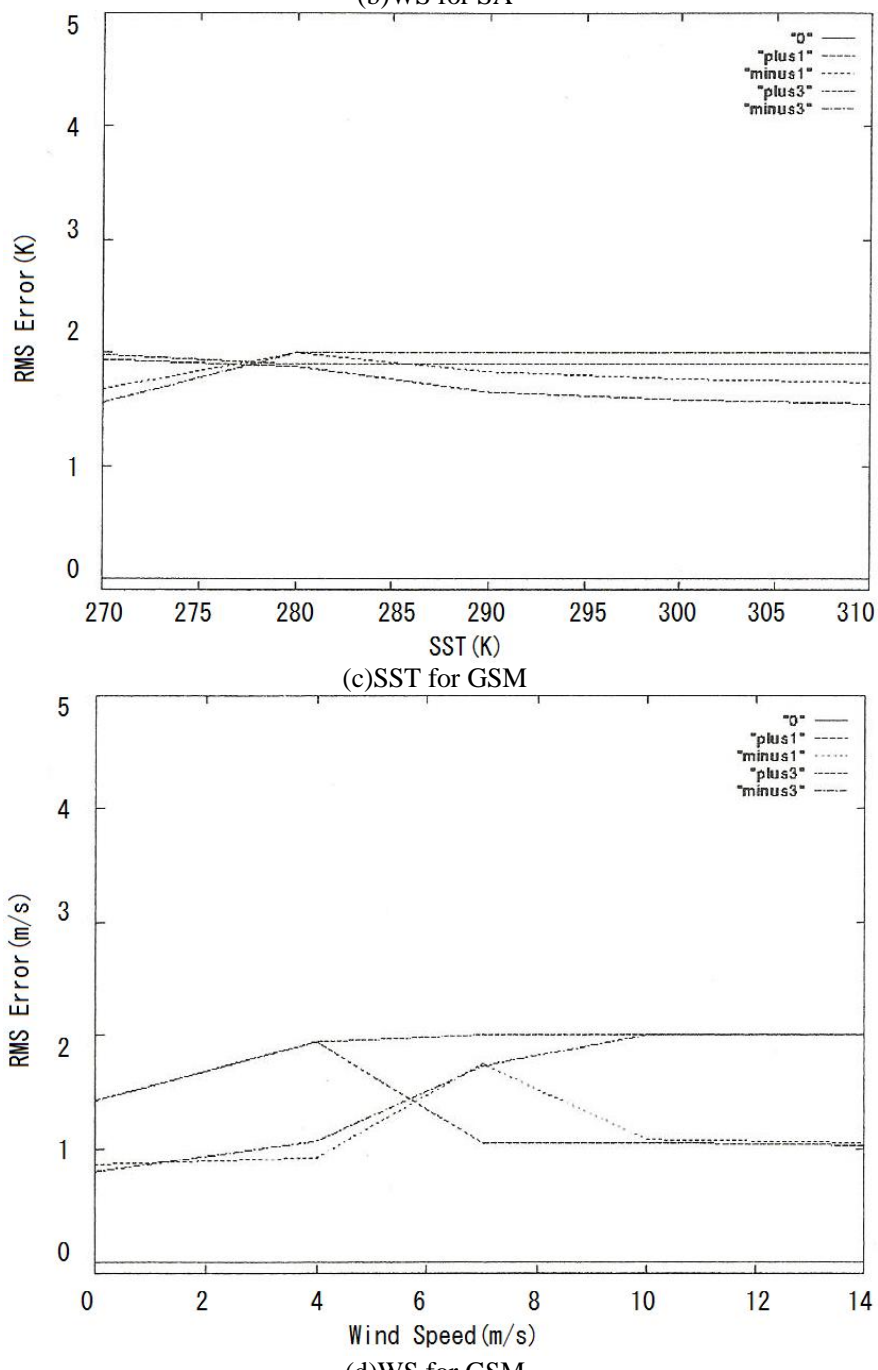

(d)WS for GSM

Fig. 3. RMS error of SA and GSM for the estimation of SST and WS with the designated bias of plus minus $1(\mathrm{~K}), 5(\mathrm{~K})$ for SST and plus minus $1(\mathrm{~m} / \mathrm{s})$, $3(\mathrm{~m} / \mathrm{s})$ for WS as well as without any bias 
As the results, it is found that RMS error of the proposed SA based method is superior to the conventional GSM method by approximately $50(\%)$ for both of SST and WS. Also, it is found that the RMS error is getting large in accordance with increasing of additive biases.

Root Mean Square: RMS error is evaluated and compared. Table 2 shows the results of RMS errors for the statistical model based method, GSM method and the proposed SA method.

TABLE II. RMS ERRor COMPARISONS AMONG THE StATISTICAL MOdEL BASED METHOD, GSM METHOD AND THE PROPOSED SA METHOD

\begin{tabular}{|l|l|l|}
\hline Method & SST(K) & WS(m/s) \\
\hline Statistical Approach & 0.46 & 0.66 \\
\hline GSM & 0.274 & 0.327 \\
\hline SA & 0.492 & 0.435 \\
\hline
\end{tabular}

If the biases are added to the theoretical SST and WS intentionally, then the RMS errors are varied as shown in Table 3 for GSM method while those for SA method is shown in Table 4.

TABLE III. RMS ERRORS OF SST AND WS FOR GSM METHOD AS A FUNCTION OF DEVIATIONS

\begin{tabular}{|l|l|l|}
\hline Biases & SST $(\mathrm{K})$ & WS $(\mathrm{m} / \mathrm{s})$ \\
\hline 0 & 0 & 0 \\
\hline+1 & 1.722 & 1.302 \\
\hline-1 & 1.805 & 1.135 \\
\hline+3 & 1.916 & 1.874 \\
\hline-3 & 1.912 & 1.520 \\
\hline
\end{tabular}

TABLE IV. RMS ERRORS OF SST AND WS FOR SA METHOD AS A FUNCTION OF DEVIATIONS

\begin{tabular}{|l|l|l|}
\hline Deviation & SST(K) & WS(m/s) \\
\hline 0 & 0.809 & 0.739 \\
\hline+1 & 1.146 & 1.132 \\
\hline-1 & 1.520 & 0.853 \\
\hline+3 & 1.064 & 1.127 \\
\hline-3 & 1.169 & 1.363 \\
\hline
\end{tabular}

By using the actual brightness temperature data of TMI, SST and WS estimation errors are evaluated. Table 5 shows the estimated SST and WS as well as RMS errors for the cases of SST are set at 292, 294 and 296(K). In these cases, the estimated SST and WS are compared to the actual TMI data derived SST and WS. RMS error of SST shows around 4.5(K) while that of WS is approximately $3.7(\mathrm{~m} / \mathrm{s})$ respectively.

TABLE V. ESTIMATED SST AND WS AS WELL AS RMS ERRORS FOR THE CASES OF SST ARE SET AT 292, 294 AND 296(K)

\begin{tabular}{|l|l|l|l|l|}
\hline Case & SST(K) & RMSE(SST) & WS(m/s) & RMSE(WS) \\
\hline $296(\mathrm{~K})$ & 291.8 & $4.297(\mathrm{~K})$ & 6.708 & $4.036(\mathrm{~m} / \mathrm{s})$ \\
\hline $294(\mathrm{~K})$ & 289.498 & $4.619(\mathrm{~K})$ & 7.313 & $2.997(\mathrm{~m} / \mathrm{s})$ \\
\hline $292(\mathrm{~K})$ & 287.348 & $4.753(\mathrm{~K})$ & 6.604 & $4.156(\mathrm{~m} / \mathrm{s})$ \\
\hline
\end{tabular}

As the results from the experiments, it is found that the proposed SA based method is superior to the statistical model based method and the GSM method.

\section{CONCLUSION}

Comparative study of optimization methods for estimation sea surface temperature and ocean wind with microwave radiometer data is conducted. The well known mesh method
(Grid Search Method: GSM), regressive method, and simulated annealing method are compared. Surface emissivity is estimated with the simulated annealing and compared to the well known Thomas T. Wilheit model based emissivity. On the other hand, brightness temperature of microwave radiometer as a function of observation angle is estimated by the simulated annealing method and compares it to the actual microwave radiometer data. Also, simultaneous estimation of sea surface temperature and ocean wind speed is carried out by the simulated annealing and compared it to the estimated those by the GSM method. The experimental results show the simulated annealing which allows estimation of global optimum is superior to the other method in some extent.

As the results, it is confirmed that the well known Wilheit sea surface model is appropriate for estimation of geophysical parameters. Also, it is confirmed that the statistical model based method for geophysical parameter estimation shows marginal estimation accuracies of SST and WS $(0.46(\mathrm{~K})$ and $0.66(\mathrm{~m} / \mathrm{s})$, respectively). It is found that the estimated SST and WS are compared to the actual TMI data derived SST and WS. RMS error of SST for the proposed SA based method shows around $4.5(\mathrm{~K})$ while that of WS is approximately $3.7(\mathrm{~m} / \mathrm{s})$ respectively.

\section{ACKNOWLEDGMENT}

The author would like to thank Ms. Emi Shimomura of Saga University for her effort to conduct the experiments.

\section{REFERENCES}

[1] Kohei Arai, Preliminary Assessment of Radiometric Accuracy for MOS1 Sensors, International Journal of Remote Sensing, Vol.9, No.1, pp.512, Apr.1988.

[2] K.Tachi, Kohei Arai and Y.Satoh, Advanced Microwave Scanning Radiometer -Requirements and Preliminary Design Study-, IEEE Trans. on Geoscience and Remote Sensing, Vol.27, No.2, pp.177-183, Jan.1989.

[3] Kenbu Teramoto, Kohei Arai, Toshio Imatani, Antenna Pattern Correction of Microwave Radiometer Based on 凸 Projection Method, Journal of Remote Sensing Society of Japan, Vol.15, No.4, pp.38-49, Sep.1994.

[4] Kohei Arai, E.Ishiyama and Y.Terayama, A method for ice concentration estimation with microwave radiometer data by means of inversion techniques, Advances in Space Research, Vol.16, No.10, pp.129-132, A31-32, Jul.1994.

[5] Kohei Arai, Kenbu Teramoto, Algorithm of Multi-Frequency Microwave Radiometer Data Correction, Notes of Meteorological Research, No.187, pp.169-176, Aug.1996.

[6] Kohei Arai and J.Sakakibara, Estimation of SST, wind speed and water vapor with microwave radiometer data based on simulated annealing, Advances in Space Research, 37, 12, 2202-2207, 2006.

[7] Kohei Arai, Kenta Azuma, Ocean wind speed estimation accuracy improvement using microwave radiometer data taking into account wind direction dependency of the observed brightness temperature, Journal of Remote Sensing Society of Japan, 27, 5, 465-473, 2007

[8] Kohei Arai, Kenta Azuma, Rainfall rate estimation with AMSR data on board AQUA satellite taking into account geometric relation between the microwave radiometer and observation targets, Journal of Japan Society of Photogrammetry and Remote Sensing, 49, 1, 32-40, 2010

[9] K.Arai, Simultaneous estimation of geophysical parameters with microwave radiometer data based on accelerated Simulated Annealing: SA, International Journal of Advanced Computer Science and Applications, 3, 7, 90-95, 2012.

[10] K.Arai, Nonlinear Optimization Based Sea Surface Temperature: SST Estimation Methods with Remote Sensing Satellite Based Microwave 
Scanning Radiometer: MSR Data, International Journal of Research and Reviews in Computer Science (IJRRCS) Vol. 3, No. 6, 1881-1886, December 2012, ISSN: 2079-2557

[11] Kohei Arai, Data fusion between microwave and thermal infrared radiometer data and its application to skin sea surface temperature, wind speed and salinity retrievals, International Journal of Advanced Computer Science and Applications, 4, 2, 239-244, 2013.

[12] K.Arai, T.Igarashi and C.Ishida, Evaluation of MOS-1 Microwave Scanning Radiometer (MSR) data in field experiments, Proc. of the 18th International Symposium on Remote Sensing of Environment, 1-8, 1984.

[13] K.Arai, T.Igarashi and Y.Takagi, Emissivity model of snowpack for passive microwave observations, Proc. of the 36th International Astronautics Federation (IAF) Congress, IAF-85-98, 1-8, 1985.

[14] K.Arai and T.Suzuki, Beam compressed microwave scanning radiometer, Proc. of the IGARSS'89, I1-2, 268-270, 1989.

[15] Y.Itoh, K.Tachi, Y.Sato and K.Arai, Advanced Microwave Scanning Radiometer: AMSR, Preliminary study, Proc. of the IGARSS'89, I1-4, 273-276, 1989.

[16] K.Arai, K.Teramoto and T.Imatani, Influence due to antenna pattern changes in brightness temperature estimation for a space based microwave radiometer, Proc. of the European ISY Conference, 311-316, 1992.

[17] K.Arai, E.Ishiyama and Y.Terayama, Method for ice concentration estimation with microwave scanning radiometer data by means of inversion, Proc. of the 30th COSPAR Congress, A3.1-032, 1993.

[18] Arai,K., E.Ishiyama and Y.Terayama, A method for ice concentration estimation with microwave radiometer data by means of inversion techniques, Proceedings of the 30th COSPAR Symposium,., A31-032, 1994

[19] Arai,K., New algorithms for ice concentration estimation with passive microwave data, Proceedings of the 1st ADEOS-II Science Symposium, Nov., 1994.

[20] K.Teramoto, K.Arai and T.Imatani, Antenna Pattern Correction for Microwave Radiometry Using A Prior Knowledge Based on Projection Convex Sets Method, Proceeding of the International Geoscience and Remote Sensing Symposium, IGARSS'95, Florence,July 1995.

[21] K.Teramoto and K.Arai, POCS Based Array Processing in Incoherent Microwave Radiometric Image Reconstruction, Proceedings of the ICASSP'96, SSAP\#615, Atlanta, May 1996.

[22] Kohei Arai, Sea Surface Temperature (SST) estimation with microwave radiometers by means of simulated annealing based on an ocean surface model, Proceedings of the NASA Oceanography Scientific Conference, Florida, USA, 2001.

[23] Kohei Arai, Sea Surface Temperature (SST) retrieval with microwave radiometer data based on simulated annealing, Proc. of the Kyushu Brunch Symposium of the electronics related Society of Japan, Asian Session, 2001.

[24] Kohei Arai and Jun Sakakibara, Estimation of SST, wind speed and water vapor with microwave radiometer data based on simulated annealing, Abstracts of the 35th Congress of the Committee on Space Research of the ICSU, A1.1-0130-04, (2004)

[25] S. Kirkpatrick, C.D. Gelett, M.P. Cecchi, Optimization by simulated annealing, Science, 220, 621-630, 1983.

[26] Debue, R. Polar Molecules, Chemical Catalog, New York, 1929.

[27] Cole, K.S., Cole, R.H. Dispersion and absorption in dielectrics. J. Chem. Phys. 9, 341-351, 1941.

[28] Cox, C.S., Munk, W.H. Measurement of the roughness of the sea surface from photographs of the sun_s glitter. J. Opt. Sci. Am. 44, 838-850, 1954.

[29] Wilheit, T.T., Chang, A.T.C. An algorithm for retrieval of ocean surface and atmospheric parameters from the observations of the Scanning Multichannel Microwave Radiometer (SMMR). Radio Sci. 15, 525-544, 1980.

[30] Waters, J.R. Absorption and emission by atmospheric gasses. in: Meeks, M.L. (Ed.), Methods of Experimental Physics, vol. 12B.Academic, Orland, 1976 (Chapter 2.3).

[31] Dong, SF; Sprintall, J; Gille, ST, Location of the antarctic polar front from AMSR-E satellite sea surface temperature measurements, JOURNAL OF PHYSICAL OCEANOGRAPHY, Nov 2006, 2075-2089.

[32] Konda, M., A. Shibata, N. Ebuchi, and K. Arai, An evaluation of the effect of the relative wind direction on the measurement of the wind and the instantaneous latent heat flux by Advanced Microwave Scanning Radiometer, J. Oceanogr., vol. 62, no. 3, pp. 395-404, 2006.

[33] Cosh, M. H., T. J. Jackson, R. Bindlish, J. Famiglietti, and D. Ryu, A comparison of an impedance probe for estimation of surface soil water content over large region, Journal of Hydrology, vol. 311, pp. 49-58, 2005.

[34] Wentz, F. AMSR Ocean Algorithm, second version of ATBD, NASA/GSFC, 2000.

\section{AUTHORS PROFILE}

Kohei Aarai He received BS, MS and PhD degrees in 1972, 1974 and 1982, respectively. He was with The Institute for Industrial Science and Technology of the University of Tokyo from April 1974 to December 1978 and also was with National Space Development Agency of Japan from January, 1979 to March, 1990. During from 1985 to 1987, he was with Canada Centre for Remote Sensing as a Post Doctoral Fellow of National Science and Engineering Research Council of Canada. He moved to Saga University as a Professor in Department of Information Science on April 1990. He was a councilor for the Aeronautics and Space related to the Technology Committee of the Ministry of Science and Technology during from 1998 to 2000. He was a councilor of Saga University for 2002 and 2003. He also was an executive councilor for the Remote Sensing Society of Japan for 2003 to 2005 . He is an Adjunct Professor of University of Arizona, USA since 1998. He also is Vice Chairman of the Commission-A of ICSU/COSPAR since 2008. He wrote 33 books and published 510 journal papers. He is Editor-in-Chief of International Journal of Advanced Computer Science and Applications as well as I ternational Journal of Intelligent Systsems and Applications. 